\title{
Are mast cells instrumental for fibrotic diseases?
}

\section{Catherine Overed-Sayer, Laura Rapley, Tomas Mustelin and Deborah L. Clarke*}

Department of Respiratory, Inflammation and Autoimmunity, Medlmmune Ltd, Cambridge, UK

\author{
Edited by: \\ Lynne Anne Murray, Medlmmune Ltd, \\ UK \\ Reviewed by: \\ Rodrigo Guabiraba, French National \\ Institute for Agricultural Research, \\ France \\ Francesca Oliviero, University of \\ Padova, Italy \\ ${ }^{*}$ Correspondence: \\ Deborah L. Clarke, Department of \\ Respiratory, Inflammation and \\ Autoimmunity, Medlmmune Ltd, \\ Granta Park, Cambridge, CB21 6GH, \\ UK \\ e-mail: clarked@medimmune.com
}

Idiopathic pulmonary fibrosis (IPF) is a fatal lung disorder of unknown etiology characterized by accumulation of lung fibroblasts and extracellular matrix deposition, ultimately leading to compromised tissue architecture and lung function capacity. IPF has a heterogeneous clinical course; however the median survival after diagnosis is only 3-5 years. The pharmaceutical and biotechnology industry has made many attempts to find effective treatments for IPF, but the disease has so far defied all attempts at therapeutic intervention. Clinical trial failures may arise for many reasons, including disease heterogeneity, lack of readily measurable clinical end points other than overall survival, and, perhaps most of all, a lack of understanding of the underlying molecular mechanisms of the progression of IPF. The precise link between inflammation and fibrosis remains unclear, but it appears that immune cells can promote fibrosis by releasing fibrogenic factors. So far, however, therapeutic approaches targeting macrophages, neutrophils, or lymphocytes have failed to alter disease pathogenesis. A new cell to garner research interest in fibrosis is the mast cell. Increased numbers of mast cells have long been known to be present in pulmonary fibrosis and clinically correlations between mast cells and fibrosis have been reported. More recent data suggests that mast cells may contribute to the fibrotic process by stimulating fibroblasts resident in the lung, thus driving the pathogenesis of the disease. In this review, we will discuss the mast cell and its physiological role in tissue repair and remodeling, as well as its pathological role in fibrotic diseases such as IPF, where the process of tissue repair and remodeling is thought to be dysregulated.

Keywords: fibrosis, mast cells, lung, idiopathic pulmonary fibrosis, TGF- $\beta$

\section{INTRODUCTION}

Idiopathic pulmonary fibrosis (IPF) is a lethal lung disorder of unknown etiology. With a median survival of 3-5 years and an increasing incidence (Dempsey, 2006; Navaratnam et al., 2013) IPF is attracting much research attention. Histologically, IPF is characterized by heterogeneity: areas of normal parenchyma are interspersed with areas of paraseptal and subpleural fibrosis (Raghu et al., 2011). The fibrotic process is often defined as an aberrant wound healing response, involving dysregulated tissue repair and remodeling (Wynn, 2011). There is epithelial damage, inflammatory cell infiltration, elevated pro-fibrotic cytokine expression, formation of fibroblastic foci, and increased extracellular matrix (ECM) deposition (Wilson and Wynn, 2009; Figure 1).

The precise link between inflammation and fibrosis remains unclear, but it appears that immune cells can promote fibrosis by releasing fibrogenic factors (Stramer et al., 2007). So far, however, therapeutic approaches targeting macrophages, neutrophils, or lymphocytes have failed to alter disease pathogenesis. A new cell to garner research interest in fibrosis is the mast cell. Indeed, increased numbers of mast cells have long been known to be present in pulmonary fibrosis (Kawanami et al., 1979), and clinically correlations between mast cells and fibrosis have been reported (Metcalfe et al., 1997). More recent data suggests that mast cells may drives the fibrotic process by stimulating fibroblasts resident in the lung (Wygrecka et al., 2013), thus driving the pathogenesis of the disease. In this review, we will discuss the mast cell and its physiological role in tissue repair and remodeling, as well as its pathological role in fibrotic diseases such as IPF, where tissue repair and remodeling are dysregulated (Wynn, 2011). Additionally, while the inflammatory roles of mast cells in asthma and atopic dermatitis are well characterized (Dougherty et al., 2010; Andersson et al., 2011a), the potential role of mast cells in mediating the tissue remodeling components of these diseases is also discussed.

\section{MAST CELL BIOLOGY}

Mast cells are innate immune cells, originally named by Paul Ehrlich in 1878 on the basis of their granular histological staining with aniline dyes. Both human and rodent mast cells originate from hematopoietic stem cells (HSCs) in the bone marrow, which give rise to common myeloid progenitors that can subsequently differentiate into mast cell precursors (Rodewald et al., 1996; Austen and Boyce, 2001; Franco et al., 2010). A number of publications suggest that mast cells could also arise from a shared basophil/mast cell progenitor. These cells had until recently only been identified in the mouse spleen (Arinobu et al., 2005), but have now also been identified in mouse bone marrow (Qi et al., 2013). In humans, common progenitor cells have been identified in the context of disease, for example in patients with myeloproliferative diseases (Zucker-Franklin, 1980). The exact origin of mast cells remains controversial, and others suggest that mast cells diverge from basophils relatively early in their differentiation (Chen et al., 2005; Mukai et al., 2012). Mast cells circulate as somewhat immature cells (Kitamura et al., 1979) and undergo 


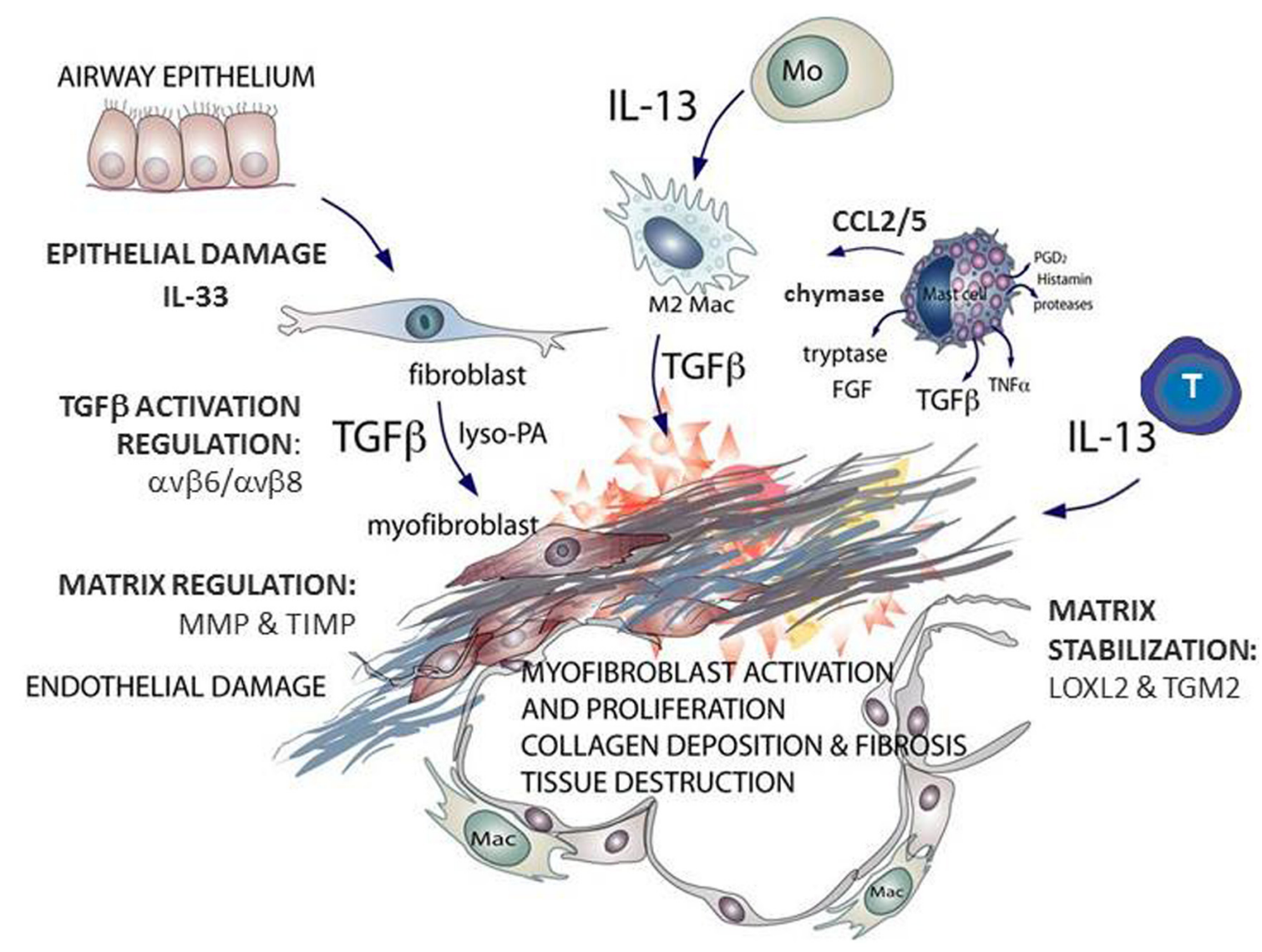

FIGURE 1 | Schematic outlining the key mast cell mediators contributing to fibrosis, the effector cells that generate transforming growth factor (TGF) $\beta$ and interleukin (IL)-13 and the enzymes associated with idiopathic pulmonary fibrosis (IPF). Multiple cell types are found at sites of lung fibrosis. Many are direct producers of extracellular matrix (ECM), or indirectly promote the generation and deposition of aberrant matrix. Mast cells generate pro-fibrotic mediators including tryptase, chymase, and chemokines that promote fibroblast activation. This figure is adapted from Clarke etal. (2013). final maturation upon entry into peripheral tissues. They reside within most tissues of the body, and are notable at sites that act as barriers to the external environment such as the skin, lung, and the intestine.

The phenotypic heterogeneity of mast cells is well known, with two major subsets being recognized. In rodents, the two subsets have different anatomical localization and expression pattern of proteases. Connective tissue mast cells (CTMCs), as the name implies, are mainly located in the connective tissues of the intestinal submucosa, the peritoneal cavity and surrounding blood vessels, and in the skin. These cells express both chymases and tryptases. In contrast, mucosal mast cells (MMCs) are usually found in the mucosal tissues of the lung and intestine and mainly express chymases (Gurish and Austen, 2012). In humans, the two subtypes of mast cells can similarly be characterized on the basis of their protease expression: $\mathrm{MC}_{\mathrm{T}}$ express tryptase only whereas $\mathrm{MC}_{\mathrm{TC}}$ contain both tryptase and chymase. The former appear to correspond to the murine mucosal type mast cell and the latter to CTMCs (Irani et al., 1986; Welle, 1997).

In addition to differences in protease content and anatomical localization, mast cells are also heterogeneous with regard to receptor expression and mediator release, and in their functional responses to various stimuli (Lowman et al., 1988; Bradding et al., 1995; Andersson et al., 2009). Some of the more well-characterized receptors are those required for the survival and/or activation of mast cells. Activation of the receptor c-kit is required for the survival, proliferation and differentiation of all mast cells via its ligand stem cell factor (SCF). A well characterized mechanism of mast cell activation is through aggregation of FceR1, the high affinity $\operatorname{IgE}$ receptor (Razin et al., 1983), although stimulation of other receptors, such as TLRs and the IL-33 receptor ST2 can also result in mast cell activation (Smith and Parikh, 1999; Varadaradjalou et al., 2003).

Upon activation, mast cells secrete an array of biologically active mediators (reviewed in Gilfillan and Beaven, 2011). Rapid mediator release occurs within minutes from pre-formed granules which can be completely emptied through exocytosis or partly emptied, but preserved for renewed release. Granules contain histamine, lipid mediators, proteoglycans, and proteases like chymases, tryptases, and carboxypeptidases (Riley and West, 1953; Hogan and Schwartz, 1997; Stevens and Adachi, 2007). Activated mast cells can also generate eicosanoids (leukotrienes and 
prostaglandins) by enzymatic biosynthesis from arachidonic acid (Boyce, 2005). They can also synthesize and release a wide array of cytokines, chemokines and growth factors, including but not limited to IL-3, IL-4, IL-5, IL-6, IL-10, IL-13, GM-CSF, TNF- $\alpha$, TGF- $\beta$, CCL2, CCL5, fibroblast growth factor (FGF) and platelet derived growth factors (PDGF; Burd et al., 1989, 1995; Plaut et al., 1989; Lukacs et al., 1996; Kanbe et al., 1999; Oliveira and Lukacs, 2001; Artuc et al., 2002), which occurs over a longer time-frame of hours rather than minutes, with the exception of TNF- $\alpha$ which may be stored and released from granules (Gordon and Galli, 1990).

The wide array of mediators that can be released from mast cells may be an indication of the versatility of mast cells and indicate that they may have many distinct effector functions. However, studying mast cell function is challenging due to the rare nature of the cells in circulation (particularly in healthy individuals) and the difficulty of isolating mast cells without affecting their activation state. In humans there are examples of rare disorders resulting from enhanced mast cell mediator release, namely systemic mast cell activation disease (MCAD). There are three forms of MCAD, the most prevalent is mast cell activation syndrome (MCAS), followed by systemic mastocytosis, then mast cell leukemia (Haenisch et al., 2012). Additionally, MCAS has been implicated as an underlying cause of fibromyalgia (Lucas et al., 2006) and irritable bowel syndrome (Frieling et al., 2011). There are however, no reports of humans with mast cells deficiencies to aid in the deciphering of their physiological roles in human physiology. In contrast, mast cell-deficient mouse strains have been used extensively to study mast cell function. However, these strains generally have loss of function mutations in the c-kit - SCF axis, complicating the picture with deficiencies in other c-kit expressing hematopoietic cells. More recently, new mouse models have been developed and will likely give a clearer picture of the functions unique to mast cells (Reber et al., 2012).

Traditionally, mast cells are thought to have evolved to confer protection against pathogens, particularly parasitic and fungal infections (Abraham and St John, 2010). Carboxypeptidase3, a mast cell product, can degrade the snake venom toxin safarotoxin (Metz et al., 2006). Other characterized effects include protection against infections with gastrointestinal helminths as well as acquired tick resistance (reviewed in Voehringer, 2013). In addition to protection against infection, other physiological roles for mast cells involving the regulation of the innate and adaptive immune system have been reported. These include tolerance against skin graft rejection, angiogenesis, as well as tissue remodeling and wound healing (Gilfillan and Beaven, 2011). The role in tissue repair and remodeling is described here, given the relevance to the pathological role of mast cells in fibrosis which is the main subject of this review.

Upon injury, there are several stages of the wound healing process; inflammation, fibroblast migration/proliferation, and remodeling. Although the pathogenesis of IPF is unclear, it is thought to involve recurrent injury to the airway epithelium and/or an aberrant wound healing response, and the stages of fibroblast proliferation/migration and tissue remodeling are particularly relevant to the fibrotic process (Wynn, 2011). Although studies of mast cell-deficient mice have reported conflicting data on the effect of mast cell deficiency on wound closure, most studies reported that mast cell depletion delayed, but did not prevent, tissue repair and remodeling (Egozi et al., 2003; Iba et al., 2004; Weller et al., 2006; Gallant-Behm et al., 2008; Shiota et al., 2010; Younan et al., 2011; Antsiferova et al., 2013). There is evidence that mast cells participate in multiple stages of the wound healing process (reviewed in Wulff and Wilgus, 2013). Within days of injury, mast cells accumulate along the edges of the wound (Trautmann et al., 2000). They likely contribute to local inflammation by stimulation of vascular permeability through secretion of histamine, lipid mediators, and VEGF, as well as through recruitment of other cell types (e.g., neutrophils via chymase; Dvorak, 2005; Weller et al., 2006; Takato et al., 2011). Although there are other aspects of wound healing (e.g., apoptosis) the processes of repair and remodeling are particularly relevant to fibrosis. Mast cells have been shown to stimulate the migration and proliferation of fibroblasts (Levi-Schaffer and Kupietzky, 1990), a key cell type in the proliferative phase of the wound healing process. These effects are mediated at least in part by cytokines and growth factors released by mast cells, including keratinocyte growth factor epidermal growth factor and platelet-derived growth factor (PDGF; Artuc et al., 1999, 2002; Noli and Miolo, 2001; Voehringer, 2013), as well as histamine and tryptase (described in more detail below; Levi-Schaffer and Piliponsky, 2003).

\section{MAST CELL PRODUCTS AS MEDIATORS OF REMODELING}

Many of the mast cell products described above as mediators of normal physiological processes, if released in excess, can trigger allergic and anaphylactic responses, and therefore also contribute to a well characterized pathological role for mast cells. In contrast to this well-established role of mast cells in acute allergy and anaphylaxis, their role in diseases involving chronic remodeling processes is much less clear. Several mast cell products are profibrotic including TGF- $\beta$, IL-13, CCL2, CCL5, IL-4, PDGF, and FGF (and this list is not exhaustive). The roles of some of these mediators in fibrotic processes are described in more detail below.

\section{TGF- $\beta$}

Although mast cells are not the sole source of TGF- $\beta 1$, this pleiotropic cytokine is perhaps the most well characterized profibrotic mediator produced by mast cells. TGF- $\beta$ has multiple functions that contribute to its role in fibrosis, including actions upon fibroblasts and myofibroblasts, key cell types involved in the pathogenesis of fibrosis. For example, TGF- $\beta$ promotes fibroblast migration and proliferation (Postlethwaite et al., 1987), as well as collagen formation and fibroblast differentiation into myofibroblasts (Fine and Goldstein, 1987; Goldstein et al., 1992; Desmouliere et al., 1993). Studies also suggest a role in epithelial-mesenchymal transition (EMT; Willis et al., 2005).

\section{TRYPTASE/CHYMASE}

Mast cell proteases tryptase and chymase have effects on both the connective tissue cells involved in fibrosis as well as the surrounding ECM. These proteases stimulate proliferation of airway smooth muscle cells, epithelium and fibroblasts, as well as fibroblast chemotaxis and myofibroblast differentiation (Ruoss et al., 1991; Brown et al., 1995; Cairns and Walls, 1996; Gruber et al., 1997). 
Mast cell tryptase can also stimulate the synthesis of type I collagen by fibroblasts (Cairns and Walls, 1997; Gruber et al., 1997), however, both proteases can also activate matrix metalloproteinases, and may therefore increase turnover of the ECM (Tchougounova et al., 2005; Iddamalgoda et al., 2008). Tryptase-mediated stimulation of fibroblast proliferation occurs via activation of the protease activated receptor PAR-2 (Akers et al., 2000), and more recently a PAR-2 dependency has also been demonstrated for tryptaseinduction of collagen and fibronectin synthesis by fibroblasts (Wygrecka et al., 2013). Furthermore, these authors hypothesized that the increase in PAR-2 expression observed in lung fibroblasts from patients with IPF could sensitize these cells to the effects of mast cell-derived tryptase (Wygrecka et al., 2013).

\section{IL-13}

The Th2 cytokine IL-13 is a pro-fibrotic mediator that is thought to promote fibrosis via TGF- $\beta$-dependent and independent mechanisms. IL-13 can induce TGF- $\beta$ production and activation in vivo and in human airway fibroblasts and this is thought to involve remodeling through IL-13R $\alpha 2$ (Lee et al., 2001; Fichtner-Feigl et al., 2006; Firszt et al., 2013). IL-13 can also directly promote fibrosis by stimulating proliferation or collagen production by fibroblasts as well as differentiation into myofibroblasts (Oriente et al., 2000; Saito et al., 2003; Ingram et al., 2004).

\section{CHEMOKINES}

CCL2 is a chemokine that signals through the receptor CCR2. In addition to displaying chemotactic activity for immune cells such as monocytes, a role in fibrosis is suggested by the ability to attract fibrocytes to the airways following lung injury (Kay, 2005). Furthermore, CCL2 can stimulate fibroblast collagen production via up-regulation of TGF- $\beta$ expression (Holgate, 2008). The interplay between TGF- $\beta$, IL-13, and CCL2 in the context of fibrosis is discussed in more detail in (Manuyakorn et al., 2013). As well as being synthesized by mast cells (Lukacs et al., 1996), CCL5 also acts as a mast cell chemoattractant (Mattoli et al., 1995). While the role of CCL5 as a fibrotic mediator is less clear compared to that of CCL2, there is some evidence that antagonism of CCL5 may be therapeutic in liver fibrosis, possibly through the modulation of monocyte subpopulations (Berres et al., 2010; Stock et al., 2013).

\section{MAST CELLS IN DISEASE}

Mast cells are key contributors to multiple diseases in which there is an element of tissue remodeling, of which asthma and atopic dermatitis are two.

\section{ASTHMA}

Asthma is traditionally an inflammatory airway disease where patients present with airflow obstruction caused by airway narrowing, an increase cellular infiltrate (eosinophils, neutrophils, T cells) to the lung and mucus plugging of the airways. The inflammation is typically Th2 driven and eosinophilic (Kay, 2005) involving many of the mediators mentioned previously. These are useful disease indictors to guide treatment; however this mechanism does not explain all aspects of asthma. There are fundamental structural changes in the asthmatic lung. The inability of anti-inflammatory treatments to reverse symptoms or the decline in lung function (Holgate, 2008) in some asthmatics is suggestive of a mechanism of uncontrolled airway remodeling significantly contributing to disease pathology (Manuyakorn et al., 2013).

Many structural changes occur in asthma, including epithelial shedding, enlarged submucosal glands, subepithelial basement membrane thickening and fibrosis as well as increased smooth muscle (Manuyakorn et al., 2013). The most striking change is in the smooth muscle which increases in amount by hyperplasia and hypertrophy, as well as spreading up and down the airway (James and Carroll, 2000), a mechanism for which remains unknown (James et al., 2005). Increasing smooth muscle contributes to airway wall thickness which is also driven by deposition of extra cellular matrix including collagen (Black et al., 2003; Howarth et al., 2004).

Mast cells have been shown to be increased in asthma (Dougherty et al., 2010; Andersson et al., 2011b). In the lung the predominant mast cell is $\mathrm{MC}_{\mathrm{T}}$ (Irani et al., 1986), however $\mathrm{MC}_{\mathrm{TC}}$, normally present in low numbers, increase with asthma severity (Balzar et al., 2011). The normal and asthmatic airways contain similar numbers of mast cells in the submucosal connective tissues, however there are increased mast cells in the epithelial layer and smooth muscle (Brightling et al., 2002; Kaur et al., 2006), as well as the bronchoalveolar lavage (BAL) fluid of patients with asthma (Shindoh et al., 1987). Increased mast cell mediators in the BAL fluid (Gibson et al., 1993) support the theory of increased presence but also increased reactivity of asthmatic mast cells over non-asthmatic mast cells. The IL-33/ST2 axis has proved to be key in mast cell biology. Mast cells are one of the highest ST2 expressing hemopoietic cell types (Moritz et al., 1998), ST2 is the receptor for the IL-1 family member, IL-33 (Schmitz et al., 2005). IL-33 is an alarmin released upon cell injury (Enoksson et al., 2011) and could therefore play a critical role in wound healing and remodeling. Both IL-33 and ST2 have been shown to be upregulated in asthma (Prefontaine et al., 2009).

The relationship between smooth muscle hyperplasia, fibrosis, and mast cells is unknown although it can be speculated that SCF producing smooth muscle cells sustain mast cell survival (Page et al., 2001), and in turn mast cells mediators such as tryptase (Brown et al., 1995) and histamine (Hollins et al., 2008) could drive this phenomenon.

\section{ATOPIC DERMATITIS}

Atopic dermatitis (AD) is a chronic allergic inflammatory disease affecting both children and adults in which mast cells are thought to be a key cell driving the immune response. The main symptom, pruritis (chronic itching) causes breakdown of the dermal barrier allowing the opportunity for bacterial entry and colonization of skin lesions, persistent inflammation, remodeling and fibrosis.

Many mediators, including histamine and Th2 cytokines that have been reported to be pro-fibrogenic and released from mast cells, are involved in AD (Greaves and Khalifa, 2004; Darsow et al., 2012; Metz et al., 2013). Additionally evidence is emerging for a role for IL-33/ST2 axis in AD (Cevikbas and Steinhoff, 2012).

There appears to be two phases of the disease which progress with severity as well as remodeling with matrix deposition causing 
toughening/fibrosis of the skin (Hamid et al., 1994). Mast cells are reportedly more activated and undergoing degranulation in mild disease, and increased numbers are associated with severe disease (Hamid et al., 1994). There is evidence of a mast cell switch from a $\mathrm{MC}_{\mathrm{TC}}$ phenotype (predominant subtype in the skin) to $\mathrm{MC}_{\mathrm{T}}$ mast cells (Irani et al., 1986).

\section{ROLE FOR MAST CELLS IN RENAL AND LUNG FIBROSIS RENAL FIBROSIS}

An association between mast cell recruitment/infiltration and fibrotic diseases has been reported in a number of organs to date. Mast cells are elevated in various kidney disorders, in which the fibrosis is characterized by increased proliferation of fibroblasts and excessive accumulation of ECM (Silver, 2013). Mast cells have been reported to play an integral part of the overall inflammatory process and play a crucial role in interstitial fibrosis in renal amyloidosis (Toth et al., 2000). Liu et al. (2010) recently confirmed these findings, and suggested a role for SCF and PAR-2 in mast cell recruitment and pathology. One study looking at a range of renal diseases revealed that the degree of renal interstitial fibrosis was well correlated with the number of infiltrating tryptase-positive mast cells (Kondo et al., 2001).

In experimental models, mast cells have been reported to be crucial to renal fibrosis induced by ureteral obstruction (Holdsworth and Summers, 2008), supporting the findings from Veerappan et al. (2012) reporting that mast cells are required for the development of renal fibrosis in the rodent unilateral ureteral obstruction model. These reports show causality for mast cells in experimental renal fibrosis and support clinical findings correlating mast cell numbers and the degree of fibrosis obstruction (Holdsworth and Summers, 2008). Additionally, the mast cell remodeling sodium chromoglycate has been reported to attenuate renal fibrosis (Summers et al., 2012), therefore it is proposed that pro-fibrotic mediators released via mast cell degranulation drive fibroblast activation and proliferation, and therefore targeting this cell type in renal disease could be attractive.

The concept of mast cells in pulmonary fibrosis is not a new one. Indeed, in the late ' 80 s, and early ' 90 s, a number of laboratories identified an increase in mast cells, or their products, in the lungs of IPF patients. In 1986, Rankin and colleagues compared the levels of histamine, a known mast cell product, in the BAL fluid of normal patients versus IPF, asthma, and sarcoidosis and reported increased histamine in IPF samples only (Rankin et al., 1987). In 1987, Shindoh and colleagues reported that when comparing basophilic cells (BCs) in the BAL fluid from patients with asthma and IPF, formalin-insensitive BCs, which were presumed to be CTMCs, were observed in BAL fluids from IPF patients whereas basophils were the major components of BCs in asthmatic patients. These compared to control subjects in which almost all of BCs were MMCs (Shindoh et al., 1987). In 1990, Fortoul and colleagues compared the number of mast cells in the lungs of IPF vs non-fibrotic lung disease vs normal, finding an approximate 10 -fold increase in interstitial mast cells compared with the non-fibrotic patients, whereas the mast cell levels were almost equal in both groups of patients in the subpleural, peribronchiolar, and perivascular areas (Fortoul and Barrios, 1990).
In 1990, Hunt and co-workers also quantified mast cells in the peribronchiolar tissue of IPF and normal human lung by using rabbit antiserum to human mast cell tryptase. They reported over a twofold increase in the connective tissue directly adjacent to the lumen of small airways and other fibrotic foci in IPF versus controllungs, which appeared to be actively degranulating (Hunt et al., 1992). In addition, Edwards et al. (2005) profiled c-kit expressing cells in interstitial lung disease (including IPF), reporting elevated c-kit + mast cells both positive for the serine proteases chymase and tryptase, as well as MMP expression in disease versus normal lung environment. Pesci et al. (1993) did not include IPF in their patient population, they did evaluate the numbers of mast cells in the fibrotic lung disorders in order to determine their role in the pathogenesis of this disorder and reported a clear increase in mast cell number which significantly correlated with the degree of fibrosis. The presence of the mast cell mediator basic FGF has also been evaluated in human interstitial lung disease to determine if mast cells and their contents drive the fibrotic response (Inoue et al., 1993). Analysis of lung tissue, BAL fluid, and serum from patients with IPF detected increased bFGF+ MC in the lung interstitium, correlating with the distribution of ECM deposition and the extent of fibrosis morphometrically, as well as elevated bFGF in the BAL fluid (Inoue et al., 1993). Moreover, increased levels of tryptase were measured in the BAL fluid of IPF patients, with tryptase-positive IPF cases reported to have a poorer outcome (Kawatani et al., 2007).

More recently Andersson and colleagues investigated the distribution pattern and phenotypes of lung mast cells in fibrosisrelated conditions. As detailed earlier, mast cell subtypes can be broadly identified by their granule content, being either typtase and chymase positive $\left(\mathrm{MC}_{\mathrm{TC}}\right.$ or CTMCs), or tryptase positive but chymase negative ( $\mathrm{MC}_{\mathrm{T}}$ orMMCs). MMCs are most frequently found in the healthy lung (Metcalfe et al., 1997). They reported that a significantly elevated number of TGF $\beta+$ mast cells in fibrotic areas of the alveolar parenchyma in patients with IPF, however no change was detected in the small airways and were decreased in the pulmonary vessels. The authors also reported an increase in mast cell expression of TGF- $\beta$ in the increased mast cells found in the alveolar parenchyma, and that the density and percentage of MCTC correlated positively with the degree of fibrosis and negatively with patient lung function (Andersson et al., 2011b). Increased activated mast cells were also reported in close proximity to fibroblast foci and alveolar type II cells in the IPF lung, as well as elevated mast cell tryptase in patients with IPF (Wygrecka et al., 2013). However, Cha et al. (2012) recently reported that although chymase positive mast cells are elevated in IPF, this correlated with a slower rate of decline in forced vital capacity suggesting a protective mechanism.

A number of experimental animal studies have now been reported to investigate the role mast cells play in the lung, typically using mast cell-deficient strains genetically engineered through a genetic deficient in c-kit. Early studies in WBB6F1$\mathrm{W} / \mathrm{Wv}$ mice reported bleomycin-induced fibrosis regardless of the mast cell deficiency (Mori et al., 1991). Additionally bleomycin could induce fibrosis using Ws/Ws mast cell-deficient rats to a similar extent as that observed in wild types (Okazaki et al., 
1998). However, more recently Veerappan et al. (2013) reported a pivotal role of mast cells in the initiating lung fibrosis. In this study, the authors administered bleomycin to mast-cell-deficient WBB6F1-W/Wv mice and their respective controls and demonstrated a protection, which was lost post restoration of the mast cell population (Veerappan et al., 2013). The authors postulate that the protective effects seen in their studies compared to the earlier studies (Mori et al., 1991; Okazaki et al., 1998), may be due to differences in experimental protocol (theirs being a 2 week model vs a 5 week model used by others). In a recent pharmacological study, berberine, a plant alkaloid was given to mice exposed to bleomycin. In this study, bleomycin induced mast cell accumulation in the lung and increased histamine levels. Berberine significantly blocked collagen accumulation as observed by a reduction in the hydroxyproline level, which corresponded with reduced histamine levels (Chitra et al., 2013), supporting a role for mast cell in the pathogenesis of lung disease.

The underlying mechanism for increased mast cells in IPF remains unknown, however a role for SCF is emerging. SCF is expressed as soluble or membrane-bound forms and promotes survival, proliferation, mobilization from the bone marrow and adhesion of hematopoietic stem cells and other progenitor cells through binding with its receptor, c-kit (Fleming et al., 1993; Lukacs et al., 1996; Domen and Weissman, 2000; Nakamura et al., 2004). In the lung this axis has been shown to be important in fibrosis as suggested by increased secretion of SCF from alveolar fibroblasts from patients with diffuse interstitial fibrosis (Fireman et al., 1999). In a mouse model of cockroach induced asthma, blockade of SCF has been shown to attenuate airway remodeling and collagen deposition in the lung (Dolgachev et al., 2009). In IPF, Wygrecka and colleagues demonstrated increased expression of membrane SCF in the IPF lung and in fibroblasts isolated from IPF tissue. Co-culture of lung fibroblasts from IPF patients with mast cells enhanced MC survival and proliferation, an effect dependent on SCF and c-kit (Wygrecka et al., 2013). This phenomenon has also been reported elsewhere, whereby SCF expressed on bronchial airway smooth muscle induces the survival, proliferation and activation of lung mast cells (Hollins et al., 2008). Additionally, blockade of SCF either genetically or using an antibody approach abrogates bleomycin-induced lung fibrosis, although mast cell measurements were not made in this model (Ding et al., 2013).

\section{SUMMARY AND FUTURE CLINICAL DIRECTIONS}

Idiopathic pulmonary fibrosis is a devastating disease for the patient. There is currently no effective treatment for this disease and the prognosis is bleak. As the term "idiopathic" indicates, the causes of the disease are unknown, as are the molecular mechanisms underpinning initiation and progression of the condition. Clearly, fibrotic processes play a key role in driving the relentless destruction of alveolar integrity, resulting eventually in a declining ability of the lung to oxygenate the blood. This decline is the root cause of the deteriorating health of the patient once the disease passes from its typically undiagnosed, early phase, into its clinically symptomatic phase. Within less than 3 years in most patients have lost much of their respiratory capacity and require drastic measures to survive.
The pharmaceutical and biotechnology industry has made many attempts to find effective treatments for IPF, but the disease has so far defied all attempts at therapeutic intervention. Clinical trial failures may arise for many reasons, including disease heterogeneity, lack of readily measurable clinical end points other than overall survival, and, perhaps most of all, a lack of understanding of the underlying molecular mechanisms of the progression of IPF.

On the positive side, with emerging new insights into the pathways and cell types involved in IPF come new opportunities for therapeutic intervention. Technologies for molecular profiling of patient tissue samples are already revealing many hitherto unexpected aspects of the disease pathology. Several new cell types, including the myofibroblast and the mast cell, offer therapeutic possibilities not previously exploited. However, the only conclusive way to determine if these cells are important for the pathogenesis of IPF is to target them with sufficiently powerful therapeutics and determine the impact on disease progression in phase 2 clinical trials. Another potentially helpful way to success may be that new therapeutics are first tested in other fibrotic conditions than IPF. Based on our current understanding of disease mechanisms, it appears likely that therapeutic interventions that are efficacious in one form of fibrotic disease will be efficacious in other fibrotic conditions. Thus, the clinically most feasible disease indication may serve as a first read-out to support the testing in more challenging indications, such as IPF. This may well be the case for mast cell-targeted therapies. We postulate that this hypothesis should be tested.

\section{REFERENCES}

Abraham, S. N., and St John, A. L. (2010). Mast cell-orchestrated immunity to pathogens. Nat. Rev. Immunol. 10, 440-452. doi: 10.1038/nri2782

Akers, I. A., Parsons, M., Hill, M. R., Hollenberg, M. D., Sanjar, S., Laurent, G. J., et al. (2000). Mast cell tryptase stimulates human lung fibroblast proliferation via protease-activated receptor-2. Am. J. Physiol. Lung Cell. Mol. Physiol. 278, L193-L201.

Andersson, C. K., Andersson-Sjoland, A., Mori, M., Hallgren, O., Pardo, A., Eriksson, L., et al. (2011a). Activated MCTC mast cells infiltrate diseased lung areas in cystic fibrosis and idiopathic pulmonary fibrosis. Respir. Res. 12, 139. doi: 10.1186/14659921-12-139

Andersson, C. K., Bergqvist, A., Mori, M., Mauad, T., Bjermer, L., and Erjefalt, J. S. (2011b). Mast cell-associated alveolar inflammation in patients with atopic uncontrolled asthma. J. Allergy Clin. Immunol. 127, 905-912. doi: 10.1016/j.jaci.2011.01.022

Andersson, C. K., Mori, M., Bjermer, L., Lofdahl, C. G., and Erjefalt, J. S. (2009). Novel site-specific mast cell subpopulations in the human lung. Thorax 64, 297305. doi: 10.1136/thx.2008.101683

Antsiferova, M., Martin, C., Huber, M., Feyerabend, T. B., Forster, A., Hartmann, K., et al. (2013). Mast cells are dispensable for normal and activin-promoted wound healing and skin carcinogenesis. J. Immunol. 191, 6147-6155. doi: 10.4049/jimmunol.1301350

Arinobu, Y., Iwasaki, H., Gurish, M. F., Mizuno, S., Shigematsu, H., Ozawa, H., et al. (2005). Developmental checkpoints of the basophil/mast cell lineages in adult murine hematopoiesis. Proc. Natl. Acad. Sci. U.S.A. 102, 18105-18110. doi: 10.1073/pnas.0509148102

Artuc, M., Hermes, B., Steckelings, U. M., Grutzkau, A., and Henz, B. M. (1999). Mast cells and their mediators in cutaneous wound healing: active participants or innocent bystanders? Exp. Dermatol. 8, 1-16. doi: 10.1111/j.16000625.1999.tb00342.x

Artuc, M., Steckelings, U. M., and Henz, B. M. (2002). Mast cell-fibroblast interactions: human mast cells as source and inducers of fibroblast and epithelial growth factors. J. Invest. Dermatol. 118, 391-395. doi: 10.1046/j.0022-202x.2001.01705.x 
Austen, K. F., and Boyce, J. A. (2001). Mast cell lineage development and phenotypic regulation. Leuk. Res. 25, 511-518. doi: 10.1016/S0145-2126(01)00030-3

Balzar, S., Fajt, M. L., Comhair, S. A., Erzurum, S. C., Bleecker, E., Busse, W. W., et al. (2011). Mast cell phenotype, location, and activation in severe asthma. Data from the Severe Asthma Research Program. Am. J. Respir. Crit. Care Med. 183, 299-309. doi: 10.1164/rccm.201002-0295OC

Berres, M. L., Koenen, R. R., Rueland, A., Zaldivar, M. M., Heinrichs, D., Sahin, H., et al. (2010). Antagonism of the chemokine Ccl5 ameliorates experimental liver fibrosis in mice. J. Clin. Invest. 120, 4129-4140. doi: 10.1172/JCI41732

Black, J. L., Burgess, J. K., and Johnson, P. R. (2003). Airway smooth muscle: its relationship to the extracellular matrix. Respir. Physiol. Neurobiol. 137, 339-346. doi: 10.1016/S1569-9048(03)00157-5

Boyce, J. A. (2005). Eicosanoid mediators of mast cells: receptors, regulation of synthesis, and pathobiologic implications. Chem. Immunol. Allergy 87, 59-79. doi: 10.1159/000087571

Bradding, P., Okayama, Y., Howarth, P. H., Church, M. K., and Holgate, S. T. (1995). Heterogeneity of human mast cells based on cytokine content. J. Immunol. 155, 297-307.

Brightling, C. E., Bradding, P., Symon, F. A., Holgate, S. T., Wardlaw, A. J., and Pavord, I. D. (2002). Mast-cell infiltration of airway smooth muscle in asthma. N. Engl. J. Med. 346, 1699-1705. doi: 10.1056/NEJMoa012705

Brown, J. K., Tyler, C. L., Jones, C. A., Ruoss, S. J., Hartmann, T., and Caughey, G. H. (1995). Tryptase, the dominant secretory granular protein in human mast cells, is a potent mitogen for cultured dog tracheal smooth muscle cells. Am. J. Respir. Cell Mol. Biol. 13, 227-236. doi: 10.1165/ajrcmb.13.2.7626290

Burd, P. R., Rogers, H. W., Gordon, J. R., Martin, C. A., Jayaraman, S., Wilson, S. D., et al. (1989). Interleukin 3-dependent and -independent mast cells stimulated with IgE and antigen express multiple cytokines. J. Exp. Med. 170, 245-257. doi: 10.1084/jem.170.1.245

Burd, P. R., Thompson, W. C., Max, E. E., and Mills, F. C. (1995). Activated mast cells produce interleukin 13. J. Exp. Med. 181, 1373-1380. doi: 10.1084/jem.181.4.1373

Cairns, J. A., and Walls, A. F. (1996). Mast cell tryptase is a mitogen for epithelial cells. Stimulation of IL-8 production and intercellular adhesion molecule- 1 expression. J. Immunol. 156, 275-283.

Cairns, J. A., and Walls, A. F. (1997). Mast cell tryptase stimulates the synthesis of type I collagen in human lung fibroblasts. J. Clin. Invest. 99, 1313-1321. doi: 10.1172/JCI119290

Cevikbas, F., and Steinhoff, M. (2012). IL-33: a novel danger signal system in atopic dermatitis. J. Invest. Dermatol. 132, 1326-1329. doi: 10.1038/jid.2012.66

Cha, S. I., Chang, C. S., Kim, E. K., Lee, J. W., Matthay, M. A., Golden, J. A., et al. (2012). Lung mast cell density defines a subpopulation of patients with idiopathic pulmonary fibrosis. Histopathology 61, 98-106. doi: 10.1111/j.13652559.2012.04197.x

Chen, C. C., Grimbaldeston, M. A., Tsai, M., Weissman, I. L., and Galli, S. J. (2005). Identification of mast cell progenitors in adult mice. Proc. Natl. Acad. Sci. U.S.A. 102, 11408-11413. doi: 10.1073/pnas.0504197102

Chitra, P., Saiprasad, G., Manikandan, R., and Sudhandiran, G. (2013). Berberine attenuates bleomycin induced pulmonary toxicity and fibrosis via suppressing NF-kappaB dependant TGF-beta activation: a biphasic experimental study. Toxicol. Lett. 219, 178-193. doi: 10.1016/j.toxlet.2013.03.009

Clarke, D. L., Carruthers, A. M., Mustelin, T., and Murray, L. A. (2013). Matrix regulation of idiopathic pulmonary fibrosis: the role of enzymes. Fibrogenesis Tissue Repair 6, 20. doi: 10.1186/1755-1536-6-20

Darsow, U., Pfab, F., Valet, M., Tolle, T. R., and Ring, J. (2012). Itch and eczema. Chem. Immunol. Allergy 96, 81-88. doi: 10.1159/000331890

Dempsey, O. J. (2006). Clinical review: idiopathic pulmonary fibrosis: past, present and future. Respir. Med. 100, 1871-1885. doi: 10.1016/j.rmed.2006. 08.017

Desmouliere, A., Geinoz, A., Gabbiani, F., and Gabbiani, G. (1993). Transforming growth factor-beta 1 induces alpha-smooth muscle actin expression in granulation tissue myofibroblasts and in quiescent and growing cultured fibroblasts. $J$. Cell Biol. 122, 103-111. doi: 10.1083/jcb.122.1.103

Ding, L., Dolgachev, V., Wu, Z., Liu, T., Nakashima, T., Wu, Z., et al. (2013). Essential role of stem cell factor-c-kit remodeling pathway in bleomycin-induced pulmonary fibrosis. J. Pathol. 230, 205-214. doi: 10.1002/path.4177

Dolgachev, V. A., Ullenbruch, M. R., Lukacs, N. W., and Phan, S. H. (2009). Role of stem cell factor and bone marrow-derived fibroblasts in airway remodeling. Am. J. Pathol. 174, 390-400. doi: 10.2353/ajpath.2009.080513
Domen, J., and Weissman, I. L. (2000). Hematopoietic stem cells need two signals to prevent apoptosis; BCL-2 can provide one of these, Kitl/c-Kit signaling the other. J. Exp. Med. 192, 1707-1718. doi: 10.1084/jem.192.12.1707

Dougherty, R. H., Sidhu, S. S., Raman, K., Solon, M., Solberg, O. D., Caughey, G. H., et al. (2010). Accumulation of intraepithelial mast cells with a unique protease phenotype in T(H)2-high asthma. J. Allergy Clin. Immunol. 125, 1046-1053. doi: 10.1016/j.jaci.2010.03.003

Dvorak, A. M. (2005). Mast cell-derived mediators of enhanced microvascular permeability, vascular permeability factor/vascular endothelial growth factor, histamine, and serotonin, cause leakage of macromolecules through a new endothelial cell permeability organelle, the vesiculo-vacuolar organelle. Chem. Immunol. Allergy 85, 185-204. doi: 10.1159/000086517

Edwards, S. T., Cruz, A. C., Donnelly, S., Dazin, P. F., Schulman, E. S., Jones, K. D., et al. (2005). C-Kit immunophenotyping and metalloproteinase expression profiles of mast cells in interstitial lung diseases. J. Pathol. 206, 279-290. doi: 10.1002/path.1780

Egozi, E. I., Ferreira, A. M., Burns, A. L., Gamelli, R. L., and Dipietro, L. A. (2003). Mast cells modulate the inflammatory but not the proliferative response in healing wounds. Wound Repair Regen. 11, 46-54. doi: 10.1046/j.1524-475X.2003.11108.x Enoksson, M., Lyberg, K., Moller-Westerberg, C., Fallon, P. G., Nilsson, G., and Lunderius-Andersson, C. (2011). Mast cells as sensors of cell injury through IL-33 recognition. J. Immunol. 186, 2523-2528. doi: 10.4049/jimmunol. 1003383

Fichtner-Feigl, S., Strober, W., Kawakami, K., Puri, R. K., and Kitani, A. (2006). IL-13 signaling through the IL-13alpha2 receptor is involved in induction of TGF-beta1 production and fibrosis. Nat. Med. 12, 99-106. doi: 10.1038/nm1332

Fine, A., and Goldstein, R. H. (1987). The effect of transforming growth factor-beta on cell proliferation and collagen formation by lung fibroblasts. J. Biol. Chem. 262, 3897-3902.

Fireman, E., Kivity, S., Shahar, I., Reshef, T., and Mekori, Y. A. (1999). Secretion of stem cell factor by alveolar fibroblasts in interstitial lung diseases. Immunol. Lett. 67, 229-236. doi: 10.1016/S0165-2478(99)00020-6

Firszt, R., Francisco, D., Church, T. D., Thomas, J. M., Ingram, J. L., and Kraft, M. (2013). Interleukin-13 induces collagen type-1 expression through matrix metalloproteinase-2 and transforming growth factor-betal in airway fibroblasts in asthma. Eur. Respir. J. doi: 10.1183/09031936.000 68712 [Epub ahead of print].

Fleming, W. H., Alpern, E. J., Uchida, N., Ikuta, K., and Weissman, I. L. (1993). Steel factor influences the distribution and activity of murine hematopoietic stem cells in vivo. Proc. Natl. Acad. Sci. U.S.A. 90, 3760-3764. doi: 10.1073/pnas.90.8.3760

Fortoul, T. I., and Barrios, R. (1990). Mast cells and idiopathic lung fibrosis. Arch. Invest. Med. 21, 5-10.

Franco, C. B., Chen, C. C., Drukker, M., Weissman, I. L., and Galli, S. J. (2010). Distinguishing mast cell and granulocyte differentiation at the single-cell level. Cell Stem Cell 6, 361-368. doi: 10.1016/j.stem.2010.02.013

Frieling, T., Meis, K., Kolck, U. W., Homann, J., Hulsdonk, A., Haars, U., et al. (2011). Evidence for mast cell activation in patients with therapy-resistant irritable bowel syndrome. Z. Gastroenterol. 49, 191-194. doi: 10.1055/s-0029-1245707

Gallant-Behm, C. L., Hildebrand, K. A., and Hart, D. A. (2008). The mast cell stabilizer ketotifen prevents development of excessive skin wound contraction and fibrosis in red Duroc pigs. Wound Repair Regen. 16, 226-233. doi: 10.1111/j.1524475X.2008.00363.X

Gibson, P. G., Allen, C. J., Yang, J. P., Wong, B. J., Dolovich, J., Denburg, J., et al. (1993). Intraepithelial mast cells in allergic and nonallergic asthma. Assessment using bronchial brushings. Am. Rev. Respir. Dis. 148, 80-86. doi: 10.1164/ajrccm/148.1.80

Gilfillan, A. M., and Beaven, M. A. (2011). Regulation of mast cell responses in health and disease. Crit. Rev. Immunol. 31, 475-529. doi: 10.1615/CritRevImmunol.v31.i6.30

Goldstein, S. M., Leong, J., Schwartz, L. B., and Cooke, D. (1992). Protease composition of exocytosed human skin mast cell protease-proteoglycan complexes. Tryptase resides in a complex distinct from chymase and carboxypeptidase. $J$. Immunol. 148, 2475-2482.

Gordon, J. R., and Galli, S. J. (1990). Mast cells as a source of both preformed and immunologically inducible TNF-alpha/cachectin. Nature 346, 274-276. doi: $10.1038 / 346274 \mathrm{a} 0$

Greaves, M. W., and Khalifa, N. (2004). Itch: more than skin deep. Int. Arch. Allergy Immunol. 135, 166-172. doi: 10.1159/000080898 
Gruber, B. L., Kew, R. R., Jelaska, A., Marchese, M. J., Garlick, J., Ren, S., et al. (1997). Human mast cells activate fibroblasts: tryptase is a fibrogenic factor stimulating collagen messenger ribonucleic acid synthesis and fibroblast chemotaxis. J. Immunol. 158, 2310-2317.

Gurish, M. F., and Austen, K. F. (2012). Developmental origin and functional specialization of mast cell subsets. Immunity 37, 25-33. doi: 10.1016/j.immuni.2012.07.003

Haenisch, B., Nothen, M. M., and Molderings, G. J. (2012). Systemic mast cell activation disease: the role of molecular genetic alterations in pathogenesis, heritability and diagnostics. Immunology 137, 197-205. doi: 10.1111/j.1365 2567.2012.03627.x

Hamid, Q., Boguniewicz, M., and Leung, D. Y. (1994). Differential in situ cytokine gene expression in acute versus chronic atopic dermatitis. J. Clin. Invest. 94, 870-876. doi: 10.1172/JCI117408

Hogan, A. D., and Schwartz, L. B. (1997). Markers of mast cell degranulation. Methods 13, 43-52. doi: 10.1006/meth.1997.0494

Holdsworth, S. R., and Summers, S. A. (2008). Role of mast cells in progressive rena diseases. J. Am. Soc. Nephrol. 19, 2254-2261. doi: 10.1681/ASN.2008010015

Holgate, S. T. (2008). Pathogenesis of asthma. Clin. Exp. Allergy 38, 872-897. doi: 10.1111/j.1365-2222.2008.02971.x

Hollins, F., Kaur, D., Yang, W., Cruse, G., Saunders, R., Sutcliffe, A., et al. (2008) Human airway smooth muscle promotes human lung mast cell survival, proliferation, and constitutive activation: cooperative roles for CADM1, stem cell factor and IL-6. J. Immunol. 181, 2772-2780.

Howarth, P. H., Knox, A. J., Amrani, Y., Tliba, O., Panettieri, R. A. Jr., and Johnson, M. (2004). Synthetic responses in airway smooth muscle. J. Allergy Clin. Immunol 114, S32-S50. doi: 10.1016/j.jaci.2004.04.041

Hunt, L. W., Colby, T. V., Weiler, D. A., Sur, S., and Butterfield, J. H. (1992) Immunofluorescent staining for mast cells in idiopathic pulmonary fibrosis: quantification and evidence for extracellular release of mast cell tryptase. Mayo Clin. Proc. 67, 941-948. doi: 10.1016/S0025-6196(12)60924-0

Iba, Y., Shibata, A., Kato, M., and Masukawa, T. (2004). Possible involvement of mast cells in collagen remodeling in the late phase of cutaneous wound healing in mice. Int. Immunopharmacol. 4, 1873-1880. doi: 10.1016/j.intimp.2004. 08.009

Iddamalgoda, A., Le, Q. T., Ito, K., Tanaka, K., Kojima, H., and Kido, H. (2008). Mast cell tryptase and photoaging: possible involvement in the degradation of extra cellular matrix and basement membrane proteins. Arch. Dermatol. Res. 300(Suppl. 1), S69-S76. doi: 10.1007/s00403-007-0806-1

Ingram, J. L., Rice, A. B., Geisenhoffer, K., Madtes, D. K., and Bonner, J. C. (2004). IL-13 and IL-1beta promote lung fibroblast growth through coordinated up-regulation of PDGF-AA and PDGF-Ralpha. FASEB J. 18, 1132-1134. doi: 10.1096/fj.03-1492fje

Inoue, Y., King, T. E. Jr., Tinkle, S. S., Dockstader, K., and Newman, L. S. (1993) Human mast cell basic fibroblast growth factor in pulmonary fibrotic disorders. Am. J. Pathol. 149, 2037-2054.

Irani, A. A., Schechter, N. M., Craig, S. S., DeBlois, G., and Schwartz, L. B. (1986). Two types of human mast cells that have distinct neutral protease compositions. Proc. Natl. Acad. Sci. U.S.A. 83, 4464-4468. doi: 10.1073/pnas.83.12.4464

James, A., and Carroll, N. (2000). Airway smooth muscle in health and disease; methods of measurement and relation to function. Eur. Respir. J. 15, 782-789. doi: 10.1034/j.1399-3003.2000.15d25.x

James, A. L., Elliot, J. G., Abramson, M. J., and Walters, E. H. (2005). Time to death, airway wall inflammation and remodelling in fatal asthma. Eur. Respir. J. 26, 429-434. doi: 10.1183/09031936.05.00146404

Kanbe, N., Kurosawa, M., Nagata, H., Saitoh, H., and Miyachi, Y. (1999). Cord blood-derived human cultured mast cells produce transforming growth factor beta1. Clin. Exp. Allergy 29, 105-113. doi: 10.1046/j.1365-2222.1999.00459.x

Kaur, D., Saunders, R., Berger, P., Siddiqui, S., Woodman, L., Wardlaw, A., et al. (2006). Airway smooth muscle and mast cell-derived CC chemokine ligand 19 mediate airway smooth muscle migration in asthma. Am. J. Respir. Crit. Care Med. 174, 1179-1188. doi: 10.1164/rccm.200603-394OC

Kawanami, O., Ferrans, V. J., Fulmer, J. D., and Crystal, R. G. (1979). Ultrastructure of pulmonary mast cells in patients with fibrotic lung disorders. Lab. Invest. 40, $717-734$

Kawatani, K., Kondo, M., Tamaoki, J., Tagaya, E., and Nagai, A. (2007). [The clinical significance of mast cell tryptase in bronchial alveolar lavage fluid in interstitial lung diseases]. Nihon Kokyuki Gakkai Zasshi 45, 848-855.
Kay, A. B. (2005). The role of eosinophils in the pathogenesis of asthma. Trends $\mathrm{Mol}$ Med. 11, 148-152. doi: 10.1016/j.molmed.2005.02.002

Kitamura, Y., Hatanaka, K., Murakami, M., and Shibata, H. (1979). Presence of mast cell precursors in peripheral blood of mice demonstrated by parabiosis. Blood 53 , 1085-1088.

Kondo, S., Kagami, S., Kido, H., Strutz, F., Muller, G. A., and Kuroda, Y. (2001). Role of mast cell tryptase in renal interstitial fibrosis. J. Am. Soc. Nephrol. 12, 1668-1676.

Lee, C. G., Homer, R. J., Zhu, Z., Lanone, S., Wang, X., Koteliansky, V., et al. (2001). Interleukin-13 induces tissue fibrosis by selectively stimulating and activating transforming growth factor beta(1). J. Exp. Med. 194, 809-821. doi: 10.1084/jem.194.6.809

Levi-Schaffer, F., and Kupietzky, A. (1990). Mast cells enhance migration and proliferation of fibroblasts into an in vitro wound. Exp. Cell Res. 188, 42-49. doi: 10.1016/0014-4827(90)90275-F

Levi-Schaffer, F., and Piliponsky, A. M. (2003). Tryptase, a novel link between allergic inflammation and fibrosis. Trends Immunol. 24, 158-161. doi: 10.1016/S14714906(03)00058-9

Liu, H., Liu, F., Peng, Y., Liu, Y., Li, L., Tu, X., et al. (2010). Role of mast cells, stem cell factor and protease-activated receptor-2 in tubulointerstitial lesions in IgA nephropathy. Inflamm. Res. 59, 551-559. doi: 10.1007/s00011-010-0159-7

Lowman, M. A., Rees, P. H., Benyon, R. C., and Church, M. K. (1988). Human mast cell heterogeneity: histamine release from mast cells dispersed from skin, lung, adenoids, tonsils, and colon in response to IgE-dependent and nonimmunologic stimuli. J. Allergy Clin. Immunol. 81, 590-597. doi: 10.1016/0091-6749(88) 90199-6

Lucas, H. J., Brauch, C. M., Settas, L., and Theoharides, T. C. (2006). Fibromyalgia: new concepts of pathogenesis and treatment. Int. J. Immunopathol. Pharmacol. $19,5-10$.

Lukacs, N. W., Strieter, R. M., Chensue, S. W., and Kunkel, S. L. (1996). Activation and regulation of chemokines in allergic airway inflammation. J. Leukoc. Biol. 59, 13-17.

Manuyakorn, W., Howarth, P. H., and Holgate, S. T. (2013). Airway remodelling in asthma and novel therapy. Asian Pac. J. Allergy Immunol. 31, 3-10.

Mattoli, S., Ackerman, V., Vittori, E., and Marini, M. (1995). Mast cell chemotactic activity of RANTES. Biochem. Biophys. Res. Commun. 209, 316-321. doi: 10.1006/bbrc. 1995.1505

Metcalfe, D. D., Baram, D., and Mekori, Y. A. (1997). Mast cells. Physiol. Rev, 77, 1033-1079.

Metz, M., Piliponsky, A. M., Chen, C. C., Lammel, V., Abrink, M., Pejler, G., et al. (2006). Mast cells can enhance resistance to snake and honeybee venoms. Science 313, 526-530. doi: 10.1126/science.1128877

Metz, M., Wahn, U., Gieler, U., Stock, P., Schmitt, J., and Blume-Peytavi, U. (2013). Chronic pruritus associated with dermatologic disease in infancy and childhood: update from an interdisciplinary group of dermatologists and pediatricians. Pediatr. Allergy Immunol. 24, 527-539. doi: 10.1111/pai.12115

Mori, H., Kawada, K., Zhang, P., Uesugi, Y., Sakamoto, O., and Koda, A. (1991). Bleomycin-induced pulmonary fibrosis in genetically mast cell-deficient WBB6F1-W/Wv mice and mechanism of the suppressive effect of tranilast, an antiallergic drug inhibiting mediator release from mast cells, on fibrosis. Int. Arch. Allergy Appl. Immunol. 95, 195-201. doi: 10.1159/000235429

Moritz, D. R., Rodewald, H. R., Gheyselinck, J., and Klemenz, R. (1998). The IL-1 receptor-related $\mathrm{T} 1$ antigen is expressed on immature and mature mast cells and on fetal blood mast cell progenitors. J. Immunol. 161, 4866-4874.

Mukai, K., BenBarak, M. J., Tachibana, M., Nishida, K., Karasuyama, H., Taniuchi, I., et al. (2012). Critical role of P1-Runx1 in mouse basophil development. Blood 120, 76-85. doi: 10.1182/blood-2011-12-399113

Nakamura, Y., Tajima, F., Ishiga, K., Yamazaki, H., Oshimura, M., Shiota, G., et al. (2004). Soluble c-kit receptor mobilizes hematopoietic stem cells to peripheral blood in mice. Exp. Hematol. 32, 390-396. doi: 10.1016/j.exphem.2004.01.004

Navaratnam, V., Fogarty, A. W., Glendening, R., McKeever, T., and Hubbard, R. B. (2013). The increasing secondary care burden of idiopathic pulmonary fibrosis: hospital admission trends in England from 1998 to 2010. Chest 143, 1078-1084. doi: $10.1378 /$ chest.12-0803

Noli, C., and Miolom, A. (2001). The mast cell in wound healing. Vet. Dermatol. 12, 303-313. doi: 10.1046/j.0959-4493.2001.00272.x

Okazaki, T., Hirota, S., Xu, Z. D., Maeyama, K., Nakama, A., Kawano, S., et al. (1998). Increase of mast cells in the liver and lung may be associated with but not a cause 
of fibrosis: demonstration using mast cell-deficient Ws/Ws rats. Lab. Invest. 78 1431-1438.

Oliveira, S. H., and Lukacs, N. W. (2001). Stem cell factor and igE-stimulated murine mast cells produce chemokines (CCL2, CCL17, CCL22) and express chemokine receptors. Inflamm. Res. 50, 168-174. doi: 10.1007/s000110050741

Oriente, A., Fedarko, N. S., Pacocha, S. E., Huang, S. K., Lichtenstein, L. M., and Essayan, D. M. (2000). Interleukin-13 modulates collagen homeostasis in human skin and keloid fibroblasts. J. Pharmacol. Exp. Ther. 292, 988-994.

Page, S., Ammit, A. J., Black, J. L., and Armour, C. L. (2001). Human mast cell and airway smooth muscle cell interactions: implications for asthma. Am. J. Physiol. Lung Cell. Mol. Physiol. 281, L1313-L1323.

Pesci, A., Bertorelli, G., Gabrielli, M., and Olivieri, D. (1993). Mast cells in fibrotic lung disorders. Chest 103, 989-996. doi: 10.1378/chest.103.4.989

Plaut, M., Pierce, J. H., Watson, C. J., Hanley-Hyde, J., Nordan, R. P., and Paul, W. E. (1989). Mast cell lines produce lymphokines in response to cross-linkage of Fc epsilon RI or to calcium ionophores. Nature 339, 64-67. doi: 10.1038/33 $9064 \mathrm{a} 0$

Postlethwaite, A. E., Keski-Oja, J., Moses, H. L., and Kang, A. H. (1987). Stimulation of the chemotactic migration of human fibroblasts by transforming growth factor beta. J. Exp. Med. 165, 251-256. doi: 10.1084/jem.165.1.251

Prefontaine, D., Lajoie-Kadoch, S., Foley, S., Audusseau, S., Olivenstein, R., Halayko, A. J., et al. (2009). Increased expression of IL-33 in severe asthma: evidence of expression by airway smooth muscle cells. J. Immunol. 183, 5094-5103. doi: 10.4049/jimmunol.0802387

Qi, X., Hong, J., Chaves, L., Zhuang, Y., Chen, Y., Wang, D., et al. (2013). Antagonistic regulation by the transcription factors C/EBPalpha and MITF specifies basophil and mast cell fates. Immunity 39, 97-110. doi: 10.1016/j.immuni.2013. 06.012

Raghu, G., Collard, H. R., Egan, J. J., Martinez, F. J., Behr, J., Brown, K. K., et al. (2011). An official ATS/ERS/JRS/ALAT statement: idiopathic pulmonary fibrosis: evidence-based guidelines for diagnosis and management. Am. J. Respir. Crit. Care Med. 183, 788-824. doi: 10.1164/rccm.2009-040GL

Rankin, J. A., Kaliner, M., and Reynolds, H. Y. (1987). Histamine levels in bronchoalveolar lavage from patients with asthma, sarcoidosis, and idiopathic pulmonary fibrosis. J. Allergy Clin. Immunol. 79, 371-377. doi: 10.1016/00916749(87)90158-8

Razin, E., Mencia-Huerta, J. M., Stevens, R. L., Lewis, R. A., Liu, F. T., Corey, E., et al. (1983). IgE-mediated release of leukotriene C4, chondroitin sulfate $\mathrm{E}$ proteoglycan, beta-hexosaminidase, and histamine from cultured bone marrowderived mouse mast cells. J. Exp. Med. 157, 189-201. doi: 10.1084/jem.157. 1.189

Reber, L. L., Marichal, T., and Galli, S. J. (2012). New models for analyzing mast cell functions in vivo. Trends Immunol. 33, 613-625. doi: 10.1016/j.it.2012.09.008

Riley, J. F., and West, G. B. (1953). The presence of histamine in tissue mast cells. J. Physiol. (Lond.) 120, 528-537.

Rodewald, H. R., Dessing, M., Dvorak, A. M., and Galli, S. J. (1996). Identification of a committed precursor for the mast cell lineage. Science 271, 818-822. doi: $10.1126 /$ science. 271.5250 .818

Ruoss, S. J., Hartmann, T., and Caughey, G. H. (1991). Mast cell tryptase is a mitogen for cultured fibroblasts. J. Clin. Invest. 88, 493-499. doi: 10.1172/JCI1 15330

Saito, A., Okazaki, H., Sugawara, I., Yamamoto, K., and Takizawa, H. (2003). Potential action of IL-4 and IL-13 as fibrogenic factors on lung fibroblasts in vitro. Int. Arch. Allergy Immunol. 132, 168-176. doi: 10.1159/000073718

Schmitz, J., Owyang, A., Oldham, E., Song, Y., Murphy, E., McClanahan, T. K., et al. (2005). IL-33, an interleukin-1-like cytokine that signals via the IL-1 receptorrelated protein ST2 and induces T helper type 2-associated cytokines. Immunity 23, 479-490. doi: 10.1016/j.immuni.2005.09.015

Shindoh, Y., Tanno, Y., Ida, S., and Takishima, T. (1987). Morphological characterization of basophilic cells in bronchoalveolar lavage fluids from patients with bronchial asthma and idiopathic pulmonary fibrosis. Tohoku J. Exp. Med. 152, 101-102. doi: 10.1620/tjem.152.101

Shiota, N., Nishikori, Y., Kakizoe, E., Shimoura, K., Niibayashi, T., Shimbori, C., et al. (2010). Pathophysiological role of skin mast cells in wound healing after scald injury: study with mast cell-deficient $\mathrm{W} / \mathrm{W}(\mathrm{V})$ mice. Int. Arch. Allergy Immunol. 151, 80-88. doi: 10.1159/000232573

Silver, R. B. (2013). Role of mast cells in renal fibrosis. Kidney Int. 84, 214. doi: 10.1038/ki.2013.72
Smith, T. J., and Parikh, S. J. (1999). HMC-1 mast cells activate human orbital fibroblasts in coculture: evidence for up-regulation of prostaglandin E2 and hyaluronan synthesis. Endocrinology 140, 3518-3525. doi: 10.1210/en.140.8.3518

Stevens, R. L., and Adachi, R. (2007). Protease-proteoglycan complexes of mouse and human mast cells and importance of their beta-tryptase-heparin complexes in inflammation and innate immunity. Immunol. Rev. 217, 155-167. doi: 10.1111/j.1600-065X.2007.00525.x

Stock, M. K., Hammerich, L., do O, N. T., Berres, M. L., Alsamman, M., Heinrichs, D., et al. (2013). Met-CCL5 modifies monocyte subpopulations during liver fibrosis regression. Int. J. Clin. Exp. Pathol. 6, 678-685.

Stramer, B. M., Mori, R., and Martin, P. (2007). The inflammation-fibrosis link? A Jekyll and Hyde role for blood cells during wound repair. J. Invest. Dermatol. 127, 1009-1017. doi: 10.1038/sj.jid.5700811

Summers, S. A., Gan, P. Y., Dewage, L., Ma, F. T., Ooi, J. D., O’Sullivan, K. M., et al. (2012). Mast cell activation and degranulation promotes renal fibrosis in experimental unilateral ureteric obstruction. Kidney Int. 82, 676-685. doi: 10.1038/ki.2012.211

Takato, H., Yasui, M., Ichikawa, Y., Waseda, Y., Inuzuka, K., Nishizawa, Y., et al. (2011). The specific chymase inhibitor TY-51469 suppresses the accumulation of neutrophils in the lung and reduces silica-induced pulmonary fibrosis in mice. Exp. Lung Res. 37, 101-108. doi: 10.3109/01902148.2010. 520815

Tchougounova, E., Lundequist, A., Fajardo, I., Winberg, J. O., Abrink, M., and Pejler, G. (2005). A key role for mast cell chymase in the activation of pro-matrix metalloprotease- 9 and pro-matrix metalloprotease-2. J. Biol. Chem. 280, 9291-9296. doi: 10.1074/jbc.M4103 96200

Toth, T., Toth-Jakatics, R., Jimi, S., and Takebayashi, S. (2000). Increased density of interstitial mast cells in amyloid A renal amyloidosis. Mod. Pathol. 13, 1020-1028. doi: 10.1038/modpathol.3880184

Trautmann, A., Toksoy, A., Engelhardt, E., Brocker, E. B., and Gillitzer, R. (2000). Mast cell involvement in normal human skin wound healing: expression of monocyte chemoattractant protein-1 is correlated with recruitment of mast cells which synthesize interleukin-4 in vivo. J. Pathol. 190, 100-106. doi: 10.1002/(SICI)1096-9896(200001)190:1<100::AID-PATH496>3.0.CO;2-Q

Varadaradjalou, S., Feger, F., Thieblemont, N., Hamouda, N. B., Pleau, J. M., Dy, M., et al. (2003). Toll-like receptor 2 (TLR2) and TLR4 differentially activate human mast cells. Eur. J. Immunol. 33, 899-906. doi: 10.1002/eji.200323830

Veerappan, A., O’Connor, N. J., Brazin, J., Reid, A. C., Jung, A., McGee, D., et al. (2013). Mast cells: a pivotal role in pulmonary fibrosis. DNA Cell Biol. 32, 206218. doi: 10.1089/dna.2013.2005

Veerappan, A., Reid, A. C., O’Connor, N., Mora, R., Brazin, J. A., Estephan, R., et al. (2012). Mast cells are required for the development of renal fibrosis in the rodent unilateral ureteral obstruction model. Am. J. Physiol. Renal Physiol. 302, F192-F204. doi: 10.1152/ajprenal.00562.2010

Voehringer, D. (2013). Protective and pathological roles of mast cells and basophils. Nat. Rev. Immunol. 13, 362-375. doi: 10.1038/nri3427

Welle, M. (1997). Development, significance, and heterogeneity of mast cells with particular regard to the mast cell-specific proteases chymase and tryptase. $J$. Leukoc. Biol. 61, 233-245.

Weller, K., Foitzik, K., Paus, R., Syska, W., and Maurer, M. (2006). Mast cells are required for normal healing of skin wounds in mice. FASEB J. 20, 2366-2368. doi: 10.1096/fj.06-5837fje

Willis, B. C., Liebler, J. M., Luby-Phelps, K., Nicholson, A. G., Crandall, E. D., du Bois, R. M., et al. (2005). Induction of epithelial-mesenchymal transition in alveolar epithelial cells by transforming growth factor-betal: potential role in idiopathic pulmonary fibrosis. Am. J. Pathol. 166, 1321-332. doi: 10.1016/S00029440(10)62351-6

Wilson, M. S., and Wynn, T. A. (2009). Pulmonary fibrosis: pathogenesis, etiology and regulation. Mucosal Immunol. 2, 103-121. doi: 10.1038/mi.2008.85

Wulff, B. C., and Wilgus, T. A. (2013). Mast cell activity in the healing wound: more than meets the eye? Exp. Dermatol. 22, 507-510. doi: 10.1111/exd.12169

Wygrecka, M., Kwapiszewska, G., Jablonska, E., von Gerlach, S., Henneke, I., Zakrzewicz, D., et al. (2013). Role of protease-activated receptor-2 in idiopathic pulmonary fibrosis. Am. J. Respir. Crit. Care Med. 183, 1703-1714. doi: 10.1164/rccm.201009-1479OC 
Wynn, T. A. (2011). Integrating mechanisms of pulmonary fibrosis. J. Exp. Med. 208, 1339-1350. doi: 10.1084/jem.20110551

Younan, G. J., Heit, Y. I., Dastouri, P., Kekhia, H., Xing, W., Gurish, M. F., et al. (2011). Mast cells are required in the proliferation and remodeling phases of microdeformational wound therapy. Plast. Reconstr. Surg. 128, 649e-658e. doi: 10.1097/PRS.0b013e318230c55d

Zucker-Franklin, D. (1980). Ultrastructural evidence for the common origin of human mast cells and basophils. Blood 56, 534-540.

Conflict of Interest Statement: The authors declare that the research was conducted in the absence of any commercial or financial relationships that could be construed as a potential conflict of interest. The authors and editor declare that while they are currently employed by the same institution there was no conflict of interest during the review and handling of this manuscript.
Received: 04 October 2013; accepted: 20 December 2013; published online: 21 January 2014.

Citation: Overed-Sayer C, Rapley L, Mustelin T and Clarke DL (2014) Are mast cells instrumental for fibrotic diseases? Front. Pharmacol. 4:174. doi: 10.3389/ fphar.2013.00174

This article was submitted to Inflammation Pharmacology, a section of the journal Frontiers in Pharmacology.

Copyright (C) 2014 Overed-Sayer, Rapley, Mustelin and Clarke. This is an openaccess article distributed under the terms of the Creative Commons Attribution License (CC BY). The use, distribution or reproduction in other forums is permitted, provided the original author(s) or licensor are credited and that the original publication in this journal is cited, in accordance with accepted academic practice. No use, distribution or reproduction is permitted which does not comply with these terms. 